\title{
The Self-Organisation of Innovation Networks
}

\author{
Andreas Pyka \\ INRA \\ Universite Pierres Mendes, France \\ pyka@grenoble.inra.fr \\ Paul Windrum \\ MERIT/International Institute of Infonomics \\ University of Maastricht \\ p.windrum@merit.unimaas.nl
}

\begin{abstract}
This paper explores the self-organising principles of horizontally-integrated innovation networks. It is shown that such networks can self-organising in environments where the co-ordination and production of new knowledge is itself a complex, dynamic and highly non-linear processes. The paper argues the development of a self-organisation perspective of innovation networks has two advantages. First, it provides a general framework of dynamic systems in which different strands of a highly fragmented literature can be drawn together. Second, formal self-organisation modelling techniques can provide interesting new insights into the micro-macro processes driving dynamic innovation systems.

Section 1 of the paper identifies the four key principles of self-organisation: local interaction, non-linearity, thermodynamic openness and emergence. Section 2 discusses important complementarities between selforganisation theory and the 'new' theory of innovation, with the latter's emphasis of the systemic nature of knowledge production within innovation networks containing multiple private and public institutions that are connected in highly complicated and non-linear ways. This paves the way for a formal model of selforganising innovation networks presented in section 3. Section 4 discusses the main properties of the outputs generated by the model and its novel insights, section 5 summarising and considering the potential advantages for current and future research offered by the self-organisation approach.
\end{abstract}

Key words: self-organisation, innovation networks, co-operation, supply chains.

The authors would like to thank comments made by participants at the Eighth International Joseph A. Schumpeter Society Conference Manchester, United Kingdom, 28th June - 1st July 2000 


\section{Self-organisation theory}

Self-organisation theory is, to date, overwhelmingly the product of research conducted in the natural science disciplines of physics, chemistry and biology. Classic contributions to the area include Bertalanffy (1968), Haken (1978), Maturana and Varela (1980), and Prigogine (1984). Silverberg ${ }^{1}$ has argued the relevance of the self-organisation modelling approach developed by Eigen, Haken and Prigogine to economics. Yet few economists have subsequently taken up this line of research. In this paper we use this modelling approach to explore the emergence of innovation networks as a self-organising property of a dynamic economic landscape in which the co-ordination and production of new knowledge is itself a complex interactive process.

The principal characteristics of self-organising systems are outlined by Forrest and Jones (1994), and Prigogine and Nicolis (1984). The fundamental research question addressed is 'Where does order come from?'. The general laws of thermodynamics suggest that dynamic processes will follow a path of least energy until the system finds a thermodynamic equilibrium, where it will remain unless it is externally perturbed. Yet the physical world abounds with systems that maintain a high internal energy and organisation that, at least at first sight, appear to defy the laws of physics. Rather than moving towards a state of maximum entropy (total chaos) it appears that organisation arises from initially disordered conditions.

The first, and most commonly noted, condition for a self-organising physical 'system' (such as an organism or a population) is thermodynamic openness. A self-organising system exchanges energy and/or mass with its environment such that there is a nonzero flow of energy through the system. If this is not the case then, according to the second law of thermodynamics, all available usable energy in the system will be used up and the system will approach a state of maximum entropy (a thermodynamic equilibrium). A system can avoid collapsing into a local equilibrium providing it is able to import usable energy from its environment and export entropy back to it. The system does not violate the second law of thermodynamics because it is part of a larger system-environment unit. This entropy-exporting dynamic is the fundamental feature of what chemists and physicists call dissipative structures. It is often said that physical systems that are selforganising are 'far from' thermodynamic equilibrium. It is presumably more accurate to state that a system only needs to be far enough to avoid collapsing into a local equilibrium condition. If a system is neither at nor near equilibrium, then it will be undergoing some form of change in behaviour and is said to be dynamic.

A second characteristic of self-organising systems is local interaction. All natural systems have inherently local interactions, every event having some location and some

\footnotetext{
${ }^{1}$ See Silverberg 1984, 1987; Silverberg, Dosi and Orsenigo, 1988.
} 
range of effect (Kawata and Toquenaga, 1994). The focus on local interaction goes handin-hand with a bottom-up approach to systems modelling that emphasises variety in micro behaviour. Higher-level structures, it is argued, are the product of subtle differences within a heterogeneous community and the local interactions that occur between the individual members (component elements) of a community. Small differences can lead to larger differences, such as changes in the population gene frequencies, size or location that in turn can have cascading effects at still larger scales. A third characteristic of self-organisation models is non-linearity of the local interactions between different system elements. A system may contain a set of feedback loops, some of which are positive and some negative. Self-organisation can either occur when feedback loops exist among component parts, or else between lower and higher hierarchical levels.

One of the most interesting, but still imprecise, propositions of self-organisation theory is that of 'emergence' (see Crutchfield, 1994). This states that higher-order phenomena can spontaneously arise from the interactions of the lower parts. In itself this does not seem particularly contentious. Indeed emergence is a key property underpinning not just economics but all social theory. If systems were simply reducible to atomistic individuals then there would be no need to investigate the economic (or any other) interactions between individuals. Silverberg et al (1988) observe that in economics we see "complex interdependent dynamical systems unfolding in historical, i.e. irreversible, time, economic agents, who make decision today the correctness of which will only be revealed considerably later, are confronted with irreducible uncertainty and holistic interactions between each other and with aggregate variables" (Silverberg et al, 1988, p.1036, italics in original). Thus the emergence property is linked to the presence of multi-scale effects in self-organising systems. Small-scale interactions produce a 'field' at the macro level that in turn influences and modifies activity at the small-scale.

\section{2. $\quad$ The systemic nature of knowledge generation: innovation networks}

Transactions cost analysis has considered the conditions under which either markets or vertically integrated hierarchies arise as key structures for the co-ordination of economic activities in capitalist market economies. However this discussion seems to have been superseded by events. The prevalence of an intermediate form of co-ordination - the innovation network - is such that one can no longer ignore or dismiss innovation networks as an inefficient, and hence temporary, phenomenon that should give way to either a market or a hierarchical structure. The growing prevalence of networks since the 1980s suggests that the object under study has now changed to such an extent that we must explicitly consider this new phenomenon. In this section of the paper we consider how different 'stylised facts' of innovation can be brought together under the selforganisation rubric. As noted in section 1, the core concepts and modelling methods of self-organisation theory have been formulated within natural science disciplines. 
Transferring and applying these to the social domain is a non-trivial issue which must be conducted with care. Furthermore, the success of such a venture will be judged on the ability to appreciate social phenomena that cannot be appreciated under an existing (alternative) theoretical perspective. In this section we consider the synergies between the self-organisation perspective and that which underpins the 'new' theory of innovation. This prepares the way for the formal model of self-organising innovation networks presented in section 3 .

Self-organisation theory appears to complement, in many ways, the perspective of the socalled 'new' theory of innovation that has been developed over the last couple of decades. A defining characteristic of the 'new' theory is the emphasis it places on the systemic nature of knowledge production - the generation of new knowledge involves multiple private and public institutions, often in very complicated ways. One cornerstone of the 'new view' is the chain-link model of science and technology first developed by Rosenberg and Kline (Rosenberg, 1982; Kline and Rosenberg, 1986; Rosenberg, 1992). This highlights the multitude of interactions that link every phase of the innovation process within industrial organisations and the wider economic, scientific and technological environment in which organisations operate. Interactions between scientific and technological knowledge bases are complex and non-linear with numerous feedbacks (Swann, 1996). Recognising this, the chain-link model warns against privileging either the science or the technology knowledge base. The other cornerstone of the 'new view' is the proposition that problem-solving has become more complicated. On the one hand, it is argued, the number of different knowledge fields that must be mastered has proliferated (Senker and Faulkner, 1992; Kodama, 1996). On the other, the rate of technical and scientific change seems to be increasing. Consequently no single firm (or any other institution for that matter) has sufficient resources to keep at the leading-edge of knowledge. The upshot is the emergence of a new organisational structure - innovation networks - that encompass heterogeneous (private and public sector) institutions and knowledge fields.

In this paper we focus on the rationale for co-operative behaviour and its implications for firms' competitive strategies. Specifically, we are interested in co-operation within horizontally structured innovation networks that are open with respect to their environment. Co-operation can take one of two forms; formal knowledge exchange through collaborative R\&D and informal knowledge exchange. The advantage of formal collaborative relationships is the ability to put in place IPR clauses, confidentially agreements and other contractual measures designed to safeguard the firm against knowledge spill-over. However, these measures are costly to instigate and police. By contrast, a key attraction of informal relationships is their low co-ordination costs; they are relatively simple, uncomplicated and more flexible (Hakanson H. and Johanson, J., 1988). Von Hippel (1989) found evidence of informal know-how trading in several industries. What is interesting about von Hippel's study is his suggestion that informal know-how trading is a voluntary exchange of technical information and, as such, represents a process designed to initiate technological spill-overs. There are, he argues, 
good strategic reasons for this. If the value of the information each firm is willing to release is less than the expected value of reciprocated information then firms will exchange their knowledge voluntarily. The argument is interesting but, for this process to continue over time, strong assumptions are made about firms' abilities to evaluate and process information. Nelson (1988) has similarly suggested that a more liberal attitude towards knowledge appropriation is emerging, noting that "in some cases firms take positive actions to make their proprietary knowledge available to others" (Nelson, 1988, p. 318). However the strategic motivation cited by Nelson is very different to that put forward by von Hippel. On the one hand, Nelson reiterates the 'new' view of innovation by stating that changing environmental conditions - increasing complexity and the high speed of innovation processes - are to some extent forcing firms to a adopt a more open position. In addition he observes that diffusing certain types of know-how can be beneficial to a competitor. If a firm's proprietary technology becomes the industry standard then it gains enormous advantages because all subsequent innovations that built on that standard are readily understood and appropriated by the standard-setter. In this way Nelson makes a link with work by Arthur (1989), David (1985) and (starting from a different perspective) Katz and Shapiro (1985) on systemic lock-in to de facto standards.

Networking is a means of reducing an individual firm's exposure in a new technology field. As Abernathy and Utterback (1975) observed, a high degree of uncertainty and fluidity is associated with the creation and introduction of a radically new product. Uncertainty with respect to market size, product design, consumer tastes and technological constraints typically leads to a variety of designs being offered, reflecting different firms' bets about the future. This period of technological uncertainty ends with the emergence of one or a small number of designs that are stable enough (i.e. profitable and technically feasible) to support a significant volume of production. R\&D ties may extend beyond one product life cycle. Technological evolution is characterised by mutual interdependencies between different core technologies. New opportunities can be created through the fusion of, what were previously thought of as unrelated, knowledge fields. These cross-fertilisation effects have been discussed by Basalla (1988), Mokyr (1990), Kodama (1996), and Windrum and Birchenhall (1998). Kodama (1996) has highlighted the ability of Japanese companies, operating in stable keiretzu networks, to identify new mutual interdependencies between different core technologies.

The process of recombination and synthesis is not easy to manage or exploit. It is a creative act that invariably generates a fresh set of technical problems needing to be solved. Success not only depends on the technical competences of the individual firms making up a network but also on intra-network learning. Successful collaboration between firms holding complimentary assets requires the creation and management of linkages between their respective competencies and knowledge bases. This entails an understanding of what partners can reasonably expect of each other (their relative strengths and weaknesses) and how partners' competences can be synthesised together to create an innovative product. This type of intra-network learning is cumulative, tacit and specialised, and requires the establishment of stable, long-term relationships. In addition 
to economies due to learning by doing and using previously highlighted in the economics of innovation literature, there exist learning economies of networking that are based on routine and experience of collaboration with particular partners within innovation networks. In the presence of such a feedback, the expected long-term returns to cooperation, combined with previous sunk investments in intra-network learning, may be sufficient to keep in check short-term opportunism amongst network partners.

Multi-scale effects are also likely to be present, with a second feedback loop existing between the emerging organisational structures observed in an industry and individual decision-making. If the returns to networked $R \& D$ are frequency-dependent, i.e. returns depends on the share of firms engaged in innovation networks, then bandwagons can arise. If the number of networked firms is increasing, the gains to co-operative behaviour increase on average, making it more attractive for other firms to join an innovation network. One may reasonably expect to see a positive feedback between individual decisions to invest in collective knowledge production, the economic returns to each member of a network, and an increasingly open attitude towards further knowledge sharing. Alternatively, a negative feedback can arise if an increasing number firms decide to leave their respective networks in order to innovate independently. Then the returns to networking will decline on average, reducing still further the incentive to belong to an innovation network.

\section{Modelling the self-organisation of innovation networks}

In order to further investigate the properties giving rise to the innovation networks in complex learning environments, we present a formal model of self-organising networks that develops earlier work by Pyka (1999). In this paper we focus on the system dynamics arising from a feedback between emerging organisational structures and individual decision-making. The model contains the four key features of selforganisation described in section 1 of this paper: local interaction, non-linearity, thermodynamic openness and emergence. The model draws on Haken's synergetic approach (Haken, 1978) and is based on a Master-Equation algorithm (see Weidlich and Haag, 1983). The other notable feature of the model is its evolutionary character. Unlike more traditional neo-classical approaches, an optimisation calculus is no longer approached, but the evolution of a network structure depends on the prevailing degree of co-operation and the technological intensity of the industry.

The model contains a population of firms (agents) that collectively make up an industry. In each period, every firm must decide whether to 'join a technology network' or else 'go it alone'. A firm that joins a network chooses to act co-operatively, voluntarily disclosing its existing (including newly acquired) know-how and exchanging this knowledge with other firms. This creates the basis for an informal innovation network in which 
knowledge is pooled. Alternatively, if a firm decides to act independently then it does not disclose its existing know-how and competes directly with all other firms. The need to exchange knowledge and access external knowledge sources increases when a firm can no longer reasonably expect to be successful through its own efforts. This is particularly true if the innovation process is characterised by increasing complexity and accelerating rate of change. In making their decisions, firms are strongly influenced by the choices of other firms within the same competitive environment. Hence one would expect strong bandwagon effects as decisions to act co-operatively are affected by the numbers of firms that already engage in informal networking.

The behaviour of agents is captured in the model by 'individual transition rates'. They are the key aspect of a Master-Equation and describe the probability of an agent changing his/her behaviour. In this model the behaviour of interest is the choice between cooperative innovation through networks versus competition based on individual R\&D. There are two conditions under which there is a high probability of a firm changing its behaviour. The first is when the size of the co-operative environment is growing. If the number of co-operating firms - and hence the returns to the external knowledge pool - is growing, the gains of co-operative behaviour increases, making it more attractive for other firms to join the network. The second case occurs when the opposite conditions prevail. There is a high probability of a firm changing its behaviour when the size of the co-operative environment is declining. If the environment is initially co-operative but there is an increasing number of firms who decide to leave the network(s) and to innovate independently, then returns to the external knowledge pool will decline, further reducing the attractiveness of belonging to a network. To summarise, the probability of switching to co-operative behaviour increases as a network grows while the probability of switching to competitive behaviour increases as a network declines.

This discussion of mutual learning contains the first characteristic of self-organising systems outlined in section 1; local interaction. As discussed in section 2, technological knowledge is highly specific at two levels, at the level of the firm and the level of the technological artefact. First, technological learning is very localised in nature (Atkinson and Stiglitz, 1969). New technological improvements are not evenly spread across an economy over time but tend to concentrate within a limited range of technologies for extended periods of time. Second, new technical know-how contains highly tacit elements (Polanyi, 1962) which tends to tie new understanding and know-how to the specific skills and competencies of the firms that generate new technological knowledge.

These two aspects of technological innovation make it difficult for other firms to appropriate knowledge. Low technology spill-overs are beneficial if a firm seeks to gain a competitive advantage by independently innovating. However if, as suggested by the 'new theory' of innovation, the increasing complexity of knowledge production requires alternative innovation structures - notably innovation networks - are required, then appropriability difficulties become a disadvantage, not an advantage. Successful 
collaboration between firms with complimentary assets requires the creation of linkages between their respective competencies and knowledge bases. This does not entail perfect learning of what the other knows. Rather, it means developing an understanding of what other partners can and cannot do, how these competencies link with ones own competence, and how these can be synthesised together to create an innovative product. Clearly it takes time to build up these understandings. It is not sufficient to simply indicate a co-operative attitude. The returns to co-operative behaviour depend on the reciprocity of knowledge exchange ${ }^{2}$.

Formally, the transition rate for co-operative (co) to competitive (c) behaviour $p_{c o \rightarrow c}(x)$ depends on network size $x(x \in\{-1,1\})$.

$$
p_{c o \rightarrow c}(x)=\alpha_{1} \cdot \exp [-(\beta \cdot x)]
$$

where $\alpha_{i}$ is a frequency parameter and $\beta$ is technological intensity.

$x=-1$ when there is a purely competitive environment, $x=0$ if there is an equal distribution of co-operative and competitive firms, and $x=1$ for an innovation network in which all firms participate.

The transition rates are not perfectly symmetric with respect to switches between competitive and co-operative behaviours. This is because firms changing from competition to co-operation are confronted with networking costs. This the transition rate from competitive to co-operative behaviour $p_{c \rightarrow c o}(x)$ is given by

$$
p_{c \rightarrow c o}(x)=\alpha_{1} \cdot \exp (\beta \cdot x)-\alpha_{2} /[1+\exp (x)]
$$

The second term on the right side of transition rate (2) additionally captures positive but decreasing networking costs. First, there are some difficulties to be expected in drawing on external knowledge sources and the knowledge flows within the network are not easily used for own purposes. With an increasing size of the network, however, an adequate understanding is developed and networking costs are decreasing due to routine and experience (learning-by-networking); in other words, there are economies of scale in networking. The resulting sigmoid function is illustrated in figure 1.

\footnotetext{
${ }^{2}$ See for example Von Hippel (1989). Clark and Juma (1987) introduced the notion of evolutionary articulation characterised by an essentially resonating feature: "In order to achieve the status of useful knowledge it [the information flow] needs to undergo a process of evolutionary articulation between supplier and recipient" (Clark and Juma, 1987, p.85).
} 


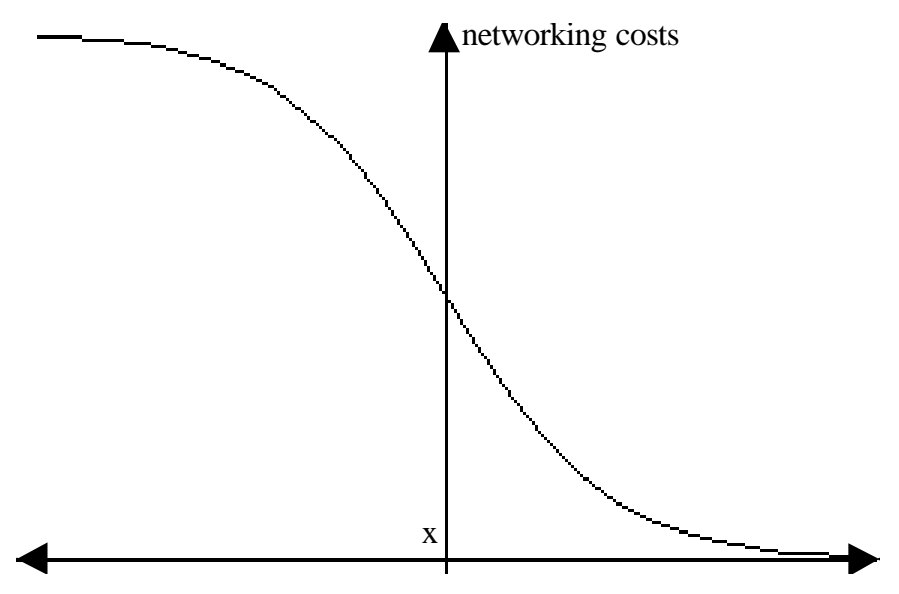

Figure 1. Networking costs

The exponential formulation of the first terms on the right side of the transition rates captures another feature of self-organising systems: non-linearity giving rise to shortterm, self-enhancing and wide-range attenuation (Gierer, 1981). Initially an expanding network will support the beneficial effects of mutual learning in a co-operative environment. However, there are two reasons for an attenuation of this effect in the long run. First, due to technological limitations, the technological opportunities of a specific technology are not unrestricted. Thus with the depletion of technological opportunities, networking becomes less attractive. Second, the heterogeneity of firms within a network decreases because they become technologically closer through the very act of sharing their know-how. Dodgson notes that "If firms in a network share knowledge over a longer period, then they will increasingly come to resemble one another with detrimental consequences for novelty and innovation" (Dodgson, 1996, p. 67). Since heterogeneity is a necessary precondition for spill-overs with high information content, increasing homogeneity makes further exchanges less attractive (there is less to be 'exchanged') leading to decreasing returns to networking.

Ceteris paribus, the restricted technological opportunities of a specific technological path will tend to reduce the dynamics of technological evolution, with similar effects on the importance of networking and mutual learning. However, as discussed in section 2, technological evolution is characterised by mutual interdependencies between different core technologies. New technological opportunities can be created through the fusion of, what were previously thought of as unrelated, knowledge fields. The other key source of interaction discussed in section 2 is between technological and scientific knowledge bases, developments in each frequent having impacts on the other. These cross fertilisations restore the heterogeneity in the technological approaches of firms and correspond to the third feature of self-organising systems: thermodynamic openness. There are continuous inputs into the system, in the sense of exploring new extensive technological opportunities emerging from within as well as coming from the environment. These prevent the system from falling into a local equilibrium and reaching stasis. 
Using the transition rates of equation (1) and (2) we form a Master-Equation. Using this Master-Equation we can compute the probability of a change from one type of network configuration to another (i.e. from competition to co-operation and vice-versa) at each moment in time, and thereby determine the change in probability to meet a network of a certain size $\frac{d P(x ; t)}{d t}$ in each time period. The Master-Equation for our system of evolving informal networks is;

$$
\begin{aligned}
\frac{d P(x ; t)}{d t} & =p_{c \rightarrow c o}(x-1) \cdot P(x-1 ; t)+p_{c o \rightarrow c}(x+1) \cdot P(x+1 ; t) \\
& -p_{c \rightarrow c o}(x) \cdot P(x ; t)-p_{c o \rightarrow c}(x) \cdot P(x ; t)
\end{aligned}
$$

Thus, the master-equation is a kind of profit and loss account of the probability to meet a specific configuration $x$ at time $t$. The change of this probability depends on four different probability fluxes describing movements out and into a specific state. The above two terms with a positive sign $p_{c \rightarrow c o}(x-1) \cdot P(x-1 ; t)+p_{c o \rightarrow c}(x+1) \cdot P(x+1 ; t)$ capture the positive effect on state $x$ arising from a change in probability fluxes from a neighbouring state $(x-1$ or $x+1)$. Changes in these aggregate probability fluxes are driven by movements of individual firms between neighbouring states. These arise whenever firms decide to change their behaviour and either join an informal network $(x-1)$ or else leave a network and 'go it alone' $(x+1)$. In either case, the probability that a specific configuration $x$ (distribution of co-operative and competitive firms) will dominate the system increases as a consequence of a flux from one behavioural state to another. The below two terms with a negative sign $-p_{c \rightarrow c o}(x) \cdot P(x ; t)-p_{c o \rightarrow c}(x) \cdot P(x ; t)$ capture the negative impact of a probability flux, due to departing firms who have changed their behaviour, on the original behavioural state. Changes in firm behaviour decrease this probability, raising the probability of attraction to a neighbouring state. 


\section{Results}

There are three possible end states in this model;

(1) coexistence of co-operative and competitive behaviour

(2) dominance by co-operative behaviour

(3) dominance by competitive behaviour

Unfortunately, given its highly non-linear character, traditional analytic methods do not assist the investigation of this model's properties. Varying the mean-value equation ${ }^{3}$

$$
\dot{x}=\alpha_{1} \cdot \tanh (\beta \cdot x)-\frac{\alpha_{2} \cdot\left(0.5-\frac{x}{2}\right)}{1+\exp (x)}
$$

we find that convergence to one or other end state is sensitive to changes in the value of the technology intensity parameter $(\beta)$. Indeed, as the vector field in figure 2 shows, the system undergoes a phase transition as the value of $\beta$ is increased. For low $\beta$-values $(\beta<1)$ we find an unique mean value indicated by two arrows facing each other. This corresponds to a state of maximum entropy, as discussed in section 1. Here one cannot predict ex ante whether a firm picked at random will co-operative or competitive in behaviour.

As the value of $\beta$ increases, so we begin to see the emergence of organisation from initially disordered conditions. In the area of $\beta=1$ the mean-value becomes fuzzy, and for even higher $\beta$ values $(\beta>1)$ we observe two alternative development paths. The existence of a phase transition highlights the fourth characteristic of self-organising systems discussed in section 2: the emergence of discrete and highly differentiated macro patterns that are due to small changes in micro behaviour. In this case, significantly different network structures arise at higher technological intensities $\beta$ (i.e. fast pace of technological progress, cross-fertilisation effects, inputs from the scientific realm etc.). Below a certain threshold, co-operative and competitive behaviours can co-exist in comparatively egalitarian distributions. However, above this threshold the system tends towards end states in which one or other behaviour dominates.

\footnotetext{
${ }^{3}$ See Erdmann ( 1993, pp. 150-151).
} 


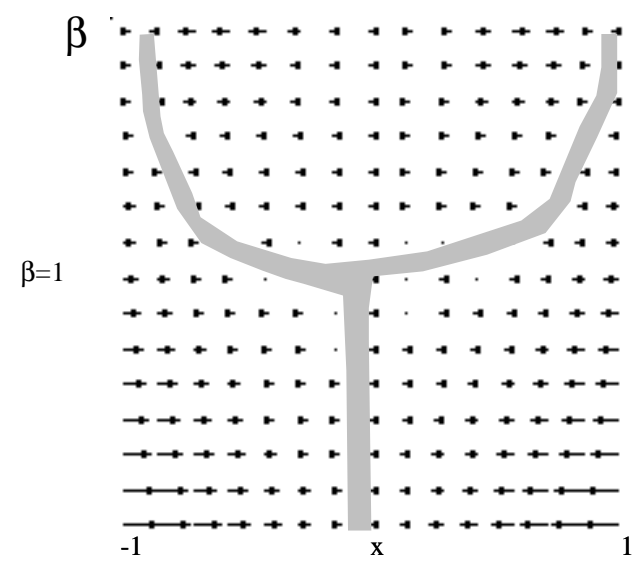

Figure 2. Mean values (grey shaded area) $x$ in dependence of technological intensity $\beta$

Given the model's non-linear character, we shall proceed to investigate its properties through a series of simulation exercises which consider the Master-Equation under a number of alternative scenarios. Before discussing the results, we need to make some preliminary remarks on simulation exercises reported here. Each simulation run consists of 2.000 periods. The frequency parameters $\alpha_{1}$ and $\alpha_{2}$ are fixed at 0.25 and 0.01 respectively for all simulation runs. Finally, the initial distribution is $P(x=0 ; 1)=1$; i.e. there is an equal probability of co-operative and competing firms at the outset of each simulation run.

In the first scenario we explore the behaviour of the system when technological intensity is relatively low $(\beta=0.8)$. Figure 3 illustrates the kind of probability distributions $P(x)$ that emerge in order to meet a certain network size $x$ over time $t$. In this case the system tends to converge to a uni-modal stationary solution with the population of firms is divided into two equivalently sized groups, one acting co-operatively and the other competitively ${ }^{4}$. In other words, in an environment where technology is not of major importance, the short-term self-enhancing and wide-range attenuation effect prevents larger networks from forming. Technological opportunities are quickly depleted and the technological resemblance of firms means a networking strategy loses importance in the course of time.

\footnotetext{
${ }^{4}$ We note that, while a macro structure can become stationary, this does not mean that there are no changes in behaviour occurring at the micro level. Rather, macro equilibrium in this model only implies that the rate of change from one behaviour to another is matched by an equal rate of change in the opposite direction.
} 


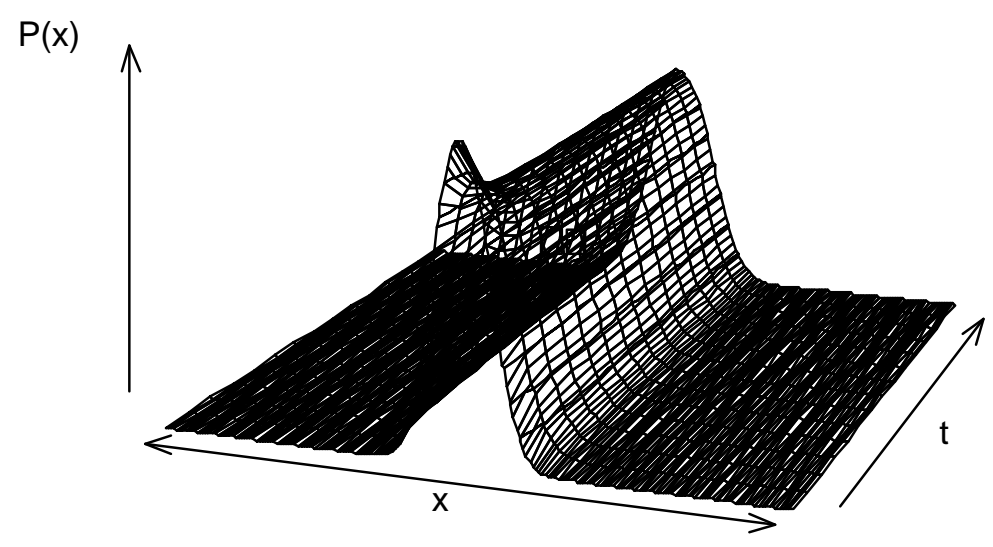

Figure 3. System development with low technological intensity $(\beta<1)$

Figure 4 illustrates a second scenario where technological intensity $\beta=1$. This approaches the critical value identified by our earlier investigation of the mean-value equation. While the median of the end state is the same as the first scenario, it takes longer for the system to reach a stationary distribution. What is more, the final distribution is considerably different to that which emerges under the first scenario (Figure 3). The distribution that emerges under the second scenario contains two local maxima, one slightly biased on the co-operative side and another that is more marked towards the non co-operative side. Thus the system is beginning to shows signs of an emergent bimodal structure, with larger co-operative and competitive clusters beginning to self-organise.

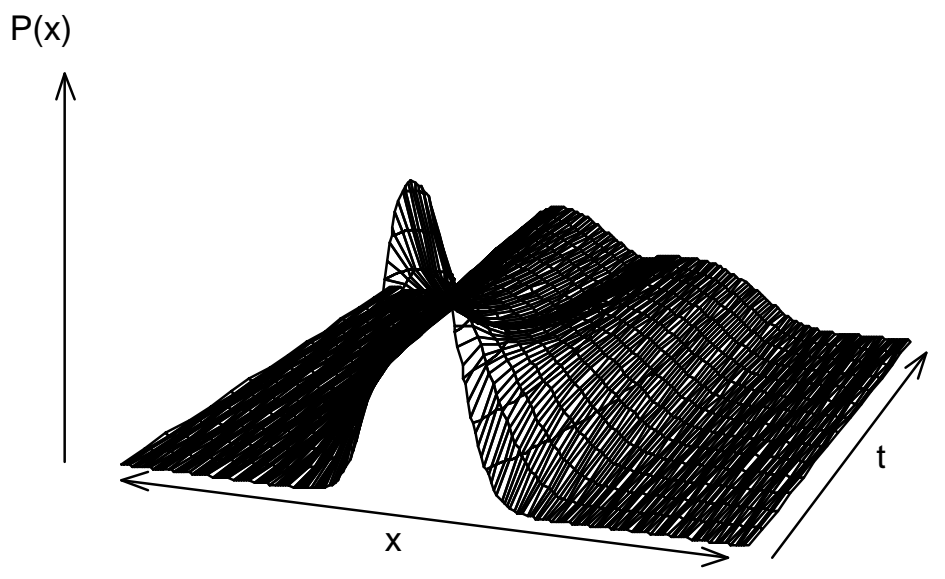

Figure 4. System development with intermediate technological intensity $(\beta=1)$ 
Figure 5 illustrates a third scenario in which there is a high technological intensity, $\beta=$ 1.25. The end state that emerges at this level of technological intensity differs significantly to the previous cases. Here the system undergoes a bifurcation such that dominance by one type of behaviour - whether this be competition or alternatively cooperation in innovation networks - is the most probable end state. It is not possible to predict ex-ante which behaviour will dominate because convergence to one or the other end state critically depends on fluctuations that occur during the phase-transition. Due to the networking costs integrated in this model, the left non co-operative peak is somewhat stronger. However an informal innovation network can self-organisationally emerge by surmounting the short-term self-enhancing and wide-range attenuation effect. In the course of time technology maintains its importance in this industry, making it attractive for firms either to stick to a competitive strategy or else create large innovation networks.

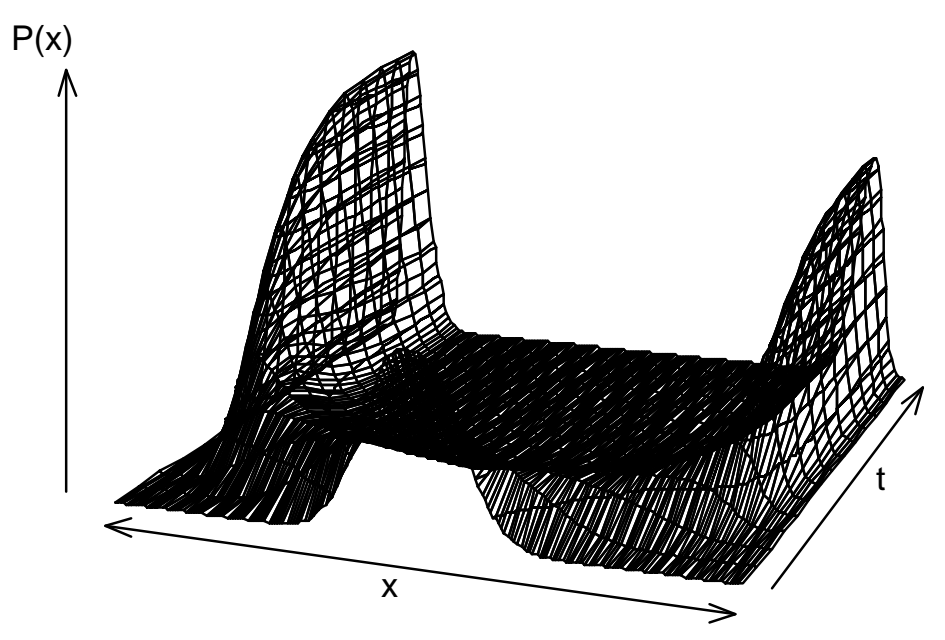

Figure 5. System development with high technological intensity $(\beta>1)$

This type of solution has been observed in empirical case studies (see Eliasson, 1995). For example, informal networks play a dominant role in sectors such as semi-conductors and biotechnology-based combinatorial chemistry. These fields of knowledge production are characterised by significant technological dynamics and by firms that are highly interdependent. Firms are apparently unable to be individually self-sufficient in the acquisition of critical complementary knowledge, participation in informal networks being a decisive mechanism through which firms seek to maintain themselves at the leading edge of the technological frontier. Yet this form of co-operative know-how exchange is more or less absent in sectors that are equally technologically dynamic and have ostensibly similar characteristics. In organic chemistry, for example, we see an industry structure in which firms are more or less self-sufficient in the production of critical complementary knowledge through in-house R\&D activities. 
The self-organisation model has a number of interesting properties. First, the results accord with von Hippel's empirical observations regarding the willingness of firms to engage in informal knowledge trading. However the model is able to generate these without making strong assumptions (as von Hippel did) about the abilities of individual agents to collect, evaluate and compare all internally- and externally-held information. In this model agents' decisions on whether to co-operate in innovation networks depend upon the size of the co-operative environment, whether this is growing or declining, and the costs of networking. If the number of co-operating firms - and hence the returns to the external knowledge pool - is growing, the gains of co-operative behaviour increases, making it more attractive for other firms to join the network.

This leads us to a second property of the model. Multi-scale effects arise in this model because local interactions between agents generate co-operative and competitive aggregate structures which in turn affect individual decision-making. Hence stable and ordered paths of change emerge as the (partly) unintentional outcome of interactions between individual agents. This result nicely illustrates Nelson's point that the basis of networked innovation is not only to be found in strategic decision-making but is strongly influenced by the industrial environment in which firms operate. Finally, the model contains multiple possible end-states. Convergence to one or other end state depends on small differences that occur at crucial points in time. This emphasises the point made by Silverberg et al regarding the nature of uncertainty in real historical time (also see Arthur (1989) and David (1985) on this point). Decisions in our model are frequency-dependent and so it is impossible to predict ex ante which type of behaviour will eventually come to dominate. Given this interdependence between firms' strategic choices, bandwagon effects can quickly spread as a result of previous changes in behaviour. As a consequence, selection of one or other end state is non-ergodic and highly sensitive to the way in which the sequence of decisions are built up. 


\section{Conclusions}

The prevalence of innovation networks is now such that one cannot dismiss them as a temporary phenomenon. In this paper we have proposed that the development of a selforganisation perspective of innovation networks is advantageous for a number of reasons. First, it provides a general framework of dynamic systems in which various strands and themes, in what remains a largely fragmented field of investigation, can be drawn together. Second, the formal modelling techniques developed in the self-organisation literature offer interesting new insights into the micro-macro processes driving system dynamics. In this paper we have focussed on the rationale for co-operative behaviour by firms within horizontally structured innovation networks.

The paper emphasised that transferring the core concepts and modelling methods of selforganisation theory from natural to social science domains is a non-trivial task that must be handled with care, the success of the venture being judged on the ability to appreciate social phenomena that cannot be appreciated under an existing (alternative) theoretical perspective. For this reason, the paper began by identifying the four key principles of self-organisation: local interaction, non-linearity, thermodynamic openness and emergence. This was followed, in section 2, by a brief overview of the 'new' theory of innovation. Self-organisation theory complements the 'new' theory of innovation, the latter emphasising the systemic nature of knowledge production within networks that contain multiple private and public institutions that are connected in highly complicated and non-linear ways. Section 2 also highlighted the way in which key stylised facts of inter-firm co-operation within formal and informal innovation networks described by previous authors can be brought together under a self-organisation rubric. This prepared the way for the formal model of self-organising innovation networks presented in section 3.

Turning to the formal results of the paper, we find the model is capable of generating two important insights into horizontally structured innovation networks. First, it can generate co-operative structures in which individual firms willing engage in informal knowledge trading. This accords with von Hippel's empirical observations. However a key advantage of the model over von Hippel's own analysis is the ability to derive this result without making strong assumptions regarding the information processing abilities of individual agents. A second result of this self-organisation model illustrates Nelson's argument that the basis of networked innovation is not just to be found in strategic decision-making but is strongly influenced by the industrial environment in which firms operate. This is due to the existence of multi-scale effects in the model, interactions between agents generating aggregate structures that in turn influence individual decisionmaking. Stable and ordered paths of change emerge through dynamic recursions between the different micro and macro levels of the model. Finally, multiple end states are permissible in the model, convergence to one or other end state depending on the 
sequence of decisions that are built up over time. This reaffirms previous analytical results regarding the nature of individual economic choices that are made in non-ergodic and inherently non-linear environments.

To conclude, the paper has sought to indicate the advantages offered by the selforganisation approach to research in innovation networks. We have emphasised that care must be taken in transferring and applying the core concepts and modelling methods of self-organisation theory to the social domain. However the rewards for this effort are potentially large. The model developed in this paper generates results that are compatible with the stylised facts of horizontally structured inter-firm networks. At the same time this is achieved without recourse to unrealistically strong assumptions about the processing capabilities of individual firms. In future work we shall seek to broaden the current discussion to include university-industry linkages and the formation of policy networks. 


\section{Bibliography}

Abernathy, W.J. and Utterback, J.M., 1975, A dynamic model of product and process innovation, Omega, 3, pp.639-656.

Arthur, W.B., 1989, Competing technologies, increasing returns and lock-in by historical events, Economic Journal, 99, pp.116-131.

Atkinson, A. B. and Stiglitz, J. E., 1969, A new view of technological change, Economic Journal, 79, 116-131.

Basalla, G., 1988, The Evolution of Technology, Cambridge University Press: Cambridge.

v. Bertalanffy, L., 1968, The Quest for a General System Theory, George Braziller: New York.

Clark, N. and Juma, C., 1987, Long Run Economics - An Evolutionary Approach to Economic Growth, Pinter Publishers: London.

Crutchfield, J. P., 1994, Is anything ever new?, in G. Cowan, D. Pines, and D. Melsner (ed.), SFI studies in the sciences of complexity XIX, Addison-Wesley: Massachusetts.

David, P., 1985, Clio and the economics of QWERTY, American Economic Review Papers and Proceedings, 75, pp.332-336.

Dodgson, M., 1996, Learning, trust and inter-firm linkages: some theoretical associations, in Coombs, R. et al. (ed.), Technological Collaboration in Industrial Innovation, Edward Elgar: London.

Eigen, M., 1971, Self-organisation of matter and the evolution of biological micromolecules, Naturwissenschaften, 58, pp.465-522.

Eliasson, G., 1995, General purpose technologies, industrial competence and economic growth - with special emphasis on the diffusion of advanced methods of integrated production, Working Paper, Royal Institute of Technology, Stockholm.

Erdmann, G., 1993, Elemente einer Evolutorischen Innovationstheorie, J. C. B. Mohr: Tübingen.

Forrest, S., and Jones, T., 1994, Modeling complex adaptive systems with echo, in R. J. Stoner and X. H. Yu (ed.), Complex Systems: mechanisms of adaptation, IOS Press: Amsterdam.

Gierer, G., 1981, Socio-economic inequalities: effects of self-enhancement, depletion and redistribution, Jahrbücher für Nationalökonomie und Statistik, Vol. 196, pp.309-331. 
Hakanson H. and Johanson, J., 1988, Formal and Informal Cooperation Strategies in International Industrial Networks, in Contractor, F. J., Lorange, P. et al. (ed.), Cooperative Strategies in International Business, Lexington Books, pp. 369-379.

Haken, H., 1978, Synergetik: Eine Einführung: Nichtgleichgewichtige Phasenübergänge und Selbstorganisation in Physik, Chemie und Biologie, Springer-Verlag: Berlin, Heidelberg, New York.

v. Hippel, E., 1989, Cooperation between rivals: informal know-how trading, in Carlsson, B. (ed.), Industrial Dynamics, Kluwer Academic Publishers:Doordrecht.

Katz, M., and Shapiro, C., 1985, Network externalities, competition and compatibility, American Economic Review, 75, pp.424-440.

Kawata, M. and Toquenaga, Y., 1994, Artificial individuals and global patterns, Trends in Ecology and Evolution, 9, pp.417-421.

Kline, S.J. and Rosenberg, N., 1986, An overview of innovation, in The Positive Sum Strategy: Harnessing Technology for Economic Growth, R. Landau and N. Rosenberg (ed.), National Academic Press: Washington D.C.

Kodama, F., 1996, Emerging Patterns of Innovation: Sources of Japan's Technological Edge, Harvard Business School Press: Cambridge, Mass.

Maturana, H. and Varela, F., 1980, Autopoiesis and Cognition: The Realization of the Living, London.

Mokyr, J., 1990, The Lever of Riches, Oxford University Press: Oxford.

Nelson, R. R.,1988, Institutions supporting technological change in the United States, in G. Dosi, C. Freeman, R. Nelson, G. Silverberg and L. Soete (eds.), Technical Change and Economic Theory, Pinter Publishers: London.

Nicolis, G. and Prigogine, I., 1977, Self-organisation in Non-Equilibrium Systems, Wiley Interscience: New York.

Nicolis, G., and Prigogine, I., 1989, Exploring complexity, W. H. Freeman: New York.

Polanyi, M., 1962, Personal Knowledge: Towards a Post-Critical Philosophy, Harper Torchbook: New York.

Prigogine, I., 1976, Order through fluctuation: self-organisation and social system, in Evolution and Consciousness, E. Jantsch and C.H. Waddington, (ed.), Addison-Wesley: New York. 
Prigogine, I. and Stengers, I., 1984, Order out of Chaos, New York.

Pyka, A., 1999, Der kollektive Innovationsprozess - Eine theoretische Analyse informeller Netzwerke und absorptiver Fähigkeiten, Duncker\&Humblot, Berlin.

Rosenberg, N., 1982, Inside the Black Box: Technology and Economics, Cambridge University Press: Cambridge.

Rosenberg, N., 1992, Scientific instrumentation and university research, Research Policy, 21, pp.381-390.

Rosenberg, N. and Nelson, R. R., 1994, American universities and technical advance in industry, Research Policy, Vol. 23 (3), pp. 323-348.

Saviotti, P.P., Pyka, A. (1999), Conceptual Framework for Biotechnology Innovation Networks, SEIN Discussion Paper, \#4.

Silverberg, G., 1984, Embodied technical progress in a dynamic economic model: the self-organisation paradigm, in Nonlinear Models of Fluctuating Growth, R. Goodwin, M. Krüger and A. Vercelli (ed.), Springer-Verlag: Berlin, Heidelberg, New York.

Silverberg, G., 1987, Technical progress, capital accumulation and effective demand: a self-organisation model, in Economic Evolution and Structural Adjustment, D. Batten, J. Casti and B. Johansson (ed.), Springer-Verlag: Berlin, Heidelberg, New York.

Silverberg, G., Dosi G. and Orsenigo, L., 1988, Innovation, diversity and diffusion: a self-organising model, The Economic Journal, 98, pp.1032-1054.

Swann, P., 1996, 'The economic value of publicly funded research', Report for DTI, April 1996, PREST, University of Manchester: Manchester.

Weidlich, W. and Haag, G., 1983, Concepts and Models of a Quantitative Sociology, Springer-Verlag: Berlin, Heidelberg, New York.

Windrum, P. and Birchenhall, C., 1998, Is life cycle theory a special case?: dominant designs and the emergence of market niches through co-evolutionary learning, Structural Change and Economic Dynamics, 9, pp.109-134. 